\title{
Do Nutritional Supplements Have a Role in Age Macular Degeneration Prevention?
}

\author{
Maria D. Pinazo-Durán, ${ }^{1,2}$ Francisco Gómez-Ulla, ${ }^{3,4,5}$ Luis Arias, ${ }^{6,7}$ Javier Araiz, \\ Ricardo Casaroli-Marano, ${ }^{9}$ Roberto Gallego-Pinazo, ${ }^{10}$ Jose J. García-Medina, ${ }^{11,12}$ \\ Maria Isabel López-Gálvez, ${ }^{13,14}$ Lucía Manzanas, ${ }^{15,16}$ Anna Salas, ${ }^{17}$ Miguel Zapata, ${ }^{18}$ \\ Manuel Diaz-Llopis, ${ }^{19,20}$ and Alfredo García-Layana ${ }^{21}$
}

${ }^{1}$ University of Valencia, Spain

${ }^{2}$ The Ophthalmic Research Unit "Santiago Grisolia", Valencia, Spain

${ }^{3}$ University of Santiago de Compostela, Spain

${ }^{4}$ The Institute Gomez-Ulla, Santiago de Compostela, Spain

${ }^{5}$ Foundation RetinaPlus, Spain

${ }^{6}$ University of Barcelona, Spain

${ }^{7}$ Retina Section, Department of Ophthalmology, Bellvitge University Hospital, Barcelona, Spain

${ }^{8}$ Vitreous and Retina Department, UPV/EHU and Instituto Clínico Quirúrgico de Oftalmología (ICQO), University of the Basque Country, Bilbao, Spain

${ }^{9}$ Clinic Institute of Ophthalmology, Clinic Hospital of Barcelona, University of Barcelona, Barcelona, Spain

${ }^{10}$ Macula Section, Department of Ophthalmology, University and Polytechnic Hospital La Fe, Valencia, Spain

${ }^{11}$ University of Murcia, General University Hospital Reina Sofia, Murcia, Spain

${ }^{12}$ Ophthalmic Reseach Unit "Santiago Grisolia", Valencia, Spain

${ }^{13}$ The University of Valladolid, Diabetes and Telemedicine Unit at the IOBA, Spain

${ }^{14}$ The Retina Unit of the Clinic University Hospital of Valladolid, Spain

${ }^{15}$ The University of Valladolid, Spain

${ }^{16}$ The Vitreo-Retina Unit of the Clinic University Hospital of Valladolid, Spain

${ }^{17}$ Research Institute of the Hospital of Vall Hebron, Barcelona, Spain

${ }^{18}$ Retina Section of the Hospital of Vall Hebron, The Universidad Autonoma de Barcelona, Barcelona, Spain

${ }^{19}$ Faculty of Medicine, University of Valencia, Valencia, Spain

${ }^{20}$ University and Polytechnic Hospital La Fe, Valencia, Spain

${ }^{21}$ University of Navarra Clinic, Pamplona, Spain

Correspondence should be addressed to Alfredo García-Layana; aglayana@unav.es

Received 22 July 2013; Accepted 12 October 2013; Published 23 January 2014

Academic Editor: Jürgen Groll

Copyright (C) 2014 Maria D. Pinazo-Durán et al. This is an open access article distributed under the Creative Commons Attribution License, which permits unrestricted use, distribution, and reproduction in any medium, provided the original work is properly cited.

Purpose. To review the proposed pathogenic mechanisms of age macular degeneration (AMD), as well as the role of antioxidants (AOX) and omega-3 fatty acids ( $\omega-3)$ supplements in AMD prevention. Materials and Methods. Current knowledge on the cellular/molecular mechanisms of AMD and the epidemiologic/experimental studies on the effects of AOX and $\omega-3$ were addressed all together with the scientific evidence and the personal opinion of professionals involved in the Retina Group of the OFTARED (Spain). Results. High dietary intakes of $\omega-3$ and macular pigments lutein/zeaxanthin are associated with lower risk of prevalence and incidence in AMD. The Age-Related Eye Disease study (AREDS) showed a beneficial effect of high doses of vitamins C, E, beta-carotene, and zinc/copper in reducing the rate of progression to advanced AMD in patients with intermediate AMD or with one-sided late AMD. The AREDS-2 study has shown that lutein and zeaxanthin may substitute beta-carotene because of its potential relationship with increased lung cancer incidence. Conclusion. Research has proved that elder people with poor diets, especially with low AOX and $\omega-3$ micronutrients intake and subsequently having low plasmatic levels, are more prone to developing AMD. Micronutrient supplementation enhances antioxidant defense and healthy eyes and might prevent/retard/modify AMD. 


\section{Introduction}

Age-related macular degeneration (AMD) is the most common cause of blindness in the Western world. AMD has a chronic progressive course and may require lifelong observation and therapy, becoming a socioeconomic problem as the proportion of the aged population is continuously increasing [1].

The evidence of extensive decline in quality of life and increased need of daily living assistance after long follow-up of patients with AMD substantiates the need to prevent vision loss and progression to blindness.

Important advances in the understanding of AMD pathogenesis have been focused on the role of oxidative damage into the retina [2]. It is clearly established that reactive oxygen species (ROS) and oxidized lipoproteins are pivotal sources of cell and tissue stress constructing adequate background for parainflammation in the aging retina. This chronic situation contributes to the development and/or progression of AMD [3]. Angiogenesis and its downstream effects are important milestones in AMD [4,5]. Furthermore, increasing evidence supports the fact that OS and apoptosis are closely linked processes and that both are implicated in the pathophysiologic mechanisms of AMD $[2,4,5]$.

All these were generating the foundation for further epidemiological and interventional studies dealing with the role of diet and nutritional supplements in the incidence and progression of AMD [6]. The age-related macular degeneration study (AREDS) showed that high doses of zinc and vitamins reduced the risk of vision loss and progression to late AMD and recommended their use in patients with intermediate AMD or late AMD in one eye. AREDS2 study has recently reported that the beta-carotene used in its first study must be changed to lutein and zeaxanthin in order to improve security without decreasing efficacy. However, AREDS2 was not able to demonstrate that omega-3 in a nutritional supplement further reduces the risk when used in addition to lutein and high doses of vitamins and zinc in a well-nourished population [7].

In addition, there is no data of the effect of nutritional supplements for AMD prevention when lower doses of antioxidants, vitamins, and zinc are used, as it happens in European countries. As a result, many ophthalmologists are confused of whether or not to use these agents in everyday clinical practice.

As a major cause of visual impairment-related qualityof-life in older adults, new clues on the redox status, angiogenesis, inflammation, as well as in the apoptosis versus cell survival regulation in AMD are needed. In this setting, the current review tries to arise data from epidemiological and interventional studies about the role of antioxidants and the omega-3 fatty acids in AMD prevention.

\section{A Fresh Look at the Pathogenic Mechanisms of AMD}

2.1. Oxidative Stress. Oxidative stress (OS) results from the imbalance between the prooxidants and the antioxidant

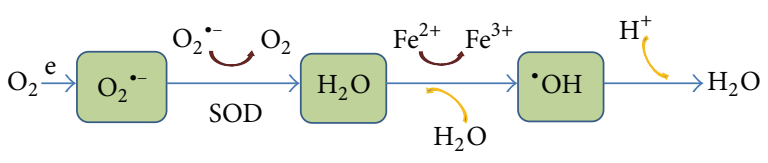

FIGURE 1: Oxidative stress (OS) is widely accepted as a key player in the initiation and progression of ocular diseases, including AMD. The chain reactions of reactive oxygen species (ROS) include the anion superoxide $\left(\mathrm{O}_{2}{ }^{--}\right)$, hydrogen peroxide $\left(\mathrm{H}_{2} \mathrm{O}_{2}\right)$, and hydroxyl radical $\left({ }^{\circ} \mathrm{OH}\right)$, all of them being able to importantly damage the cells through oxidation of lipids, proteins, and nucleic acids. These alterations lead to changes in protein function. Abbreviations: e: electron, SOD: superoxide dysmutase, and Fe: iron.

defenses leading to cellular damage and death caused by ROS [8]. The ROS are partially reduced metabolites of molecular oxygen formed through a variety of processes: normal metabolic reactions, environmental agents, or transduction pathways [9]. These ROS include oxygen free radicals, singlet oxygen, hydrogen peroxide, and their respective metabolic by products [10], as shown in Figure 1. The retina is especially vulnerable to OS because of its high polyunsaturated fatty acids (PUFAS) concentration [11-13], the elevated oxygen consumption, its exposure to light, and a wide spectrum of endogenous/exogenous injuries [14-19]. The OS role in the pathogenic mechanisms of AMD has been extensively analyzed and diverse pathogenic AMD theories have arisen. Zarbin suggested [18] that decreased oxygen delivery/metabolic "distress" may induce to the retinal pigment epithelial (RPE) cells to synthesize substances leading to choroidal neovascular growth. In this case, the RPE atrophy (probably also followed by choriocapillaris and photoreceptor atrophy), may be considered a response to decreased nutrients as well as the increased metabolic alterations in retinal areas with excessive accumulation of extracellular debris.

Macular pigment protects the macula against oxidative damage. It is mainly constituted by two dihydroxycarotenoids, lutein, and zeaxanthin, acting as an optical filter that absorbs short-wavelength visible light. Carotenoids also demonstrate antioxidant activity [20]. Eyes with a predisposition to develop AMD or which already have developed the disease have considerably less macular pigment and a greater risk of oxidative damage compared with healthy eyes [21]. In this context, clinical and experimental studies have demonstrated that photochemical macular injury is attributable to OS [21-23]. Age-related accumulation of low-molecular weight (phototoxic pro-oxidant) melanin oligomers within RPE lysosomes may contribute to a reduced photoreceptor discs phagocytosis [24]. Furthermore, the retinal pigment epithelial cell exosomes had specific signaling phosphoproteins affected by OS [25].

In this scenario, the PUFAs oxidation leads to additional ROS generation in the retina. These oxidized acids are not correctly cleaved in the lysosomes of the RPE cells and therefore are accumulated in the form of lipofuscin, which in turn is stored in Bruch's membrane as drusen. The latter can stimulate a wide variety of immune responses, including 
phagocytosis. In fact there is cumulative data indicating to lipofuscin as an important photoreactive agent and the result of the specific oxidative injury to the photoreceptor outer segments [26]. Docosahexaenoic acid (DHA22:6w3), the principal $\omega 3$-PUFA in the retina, has also been reported to exert noticeable antioxidant, anti-inflammatory, and antiangiogenic effects in both "in vivo" and "in vitro" experiments [2729].

Mitochondria are major sources of ROS, as by products of the energy metabolism. Increased ROS damages lipids, proteins, and nucleic acids. In several studies the increase in mitochondrial DNA (mtDNA) damage and mutations and the decrease in the efficacy of DNA repair have been correlated with the occurrence and the stage of AMD [30]. In fact, these authors reported that lymphocytes exhibited a higher amount of total endogenous basal and oxidative DNA damage in AMD patients. Furthermore, lymphocytes displayed an increased sensitivity to hydrogen peroxide and UV radiation, and when trying to repair these lesions they appeared to be less effective than the same cell type from non-AMD patients, suggesting that cellular response to mitochondrial and nuclear DNA damage may be involved in AMD pathogenesis. This work also demonstrated that mitochondrial DNA accumulates more DNA lesions than nuclear DNA in AMD. Synowiec et al. [31] described the association between polymorphisms of the NQO1, NOS3, and NFE2L2 genes and AMD. Other mitochondrial DNA $\mathrm{H}$ and J polymorphisms associated with protection or risk for AMD have been described by other authors [32] in a case control study. It was found that mitochondrial DNA haplogroups confer differences in risk for age-related macular degeneration.

Potential blood biomarkers of OS have extensively been described through the literature, classically involving the malondialdehyde (MDA) by product of lipid peroxidation and the 8-hydroxy-2 $2^{\prime}$-deoxyguanosine, a metabolite of nucleic acid oxidation [33]. Several molecules have also been reported as probable biomarker candidates for the early diagnosis of OS in AMD [34,35]. To explore the proteomic profile of the aqueous humor from wet AMD patients Yao et al. [36] analysed samples from wet AMD and non-AMD patients describing a significantly different protein composition between them. The specific proteins that were identified by the authors, such as galectin 3 binding protein, fibronectin, clusterin, matrix metalloproteinase-2, and pigment epithelium derived factor, may be considered as presumptive markers of wet AMD development. ROS are also produced by endoplasmic reticulum stress. Folding and secretion of proteins produce ROS and endoplasmic reticulum stress has also been described as a primary pathogenic mechanism leading to AMD [37].

It has also been shown that the iron overloaded retina is a useful model for degeneration studies. In this context Rodríguez Diez et al. [38] reported that the OS induced in the retina in the presence of iron seems to be related to AMD by means of cytosolic phospholipase A2 (cPLA2) and calciumindependent isoform (iPLA2) actions. Specifically the Group $\mathrm{V}$ secretory PLA2 (sPLA2), a member of PLA2 family, has several intracellular targets during iron-induced retinal degeneration, and its role could be related to inflammatory responses by its participation in cyclooxygenase (COX)- 2 and nuclear factor kappa B (NF- $\kappa$ B) regulation.

Further research with large clinical and epidemiological studies as well as animal models and "in vitro" experiments are urgently needed to better understand the relationship between OS and AMD.

2.2. Angiogenesis. Angiogenesis is involved in many diseases, including wet AMD $[39,40]$. Key regulators of angiogenesis are the vascular endothelial growth factor (VEGF), pigment epithelium-derived growth factor (PEDGF), fibroblast growth factor 2 (FGF2), angiopoietins, and extracellular matrix molecules (Figure 2). However, VEGF is really the molecular switch for a wide variety of neovascular conditions occurring in the eyes, through its actions on the proliferation and survival of endothelial cells and vascular permeability $[41,42]$.

Endothelial cells are particularly susceptible to exogenous and circulatory agents. It is evident that the vasculature of different organs responds differently to cytokines and growth factors. Vascular endothelial growth factor (VEGF) activates endothelial cell growth and induces angiogenesis [43-45]. Among the growth factors involved in the exudative AMD, VEGF has been shown to be a major contributor to angiogenesis, by causing a massive signalling cascade in the capillaries of the retina and choroid [46].

Bhutto et al. [47] examined the localization and levels of the VEGF and PEDGF (an antiangiogenic factor) in aged human choroid for determining if the localization or their levels changed in AMD eyes. Data from this study suggest a critical balance between PEDGF and VEGF. In addition, PEDGF may counteract the angiogenic potential of VEGF. The authors concluded that a decrease in PEDGF may disrupt the balance by favouring the formation of choroidal neovascularization in AMD.

Stefater et al. [48] reported a new pathway through myeloid cells that utilize the integration/Wingless (Wnt) pathway to regulate expression of human receptor-type tyrosine kinase gene (Flt1) and angiogenesis (Figure 2). This gene encodes a protein called VEGF receptor-1 that inhibits vascular growth by binding VEGF. It seems that Flt1 expression can also be regulated so that when increasing it blocks VEGF and vascular branching, or when lowering it permits VEGF to increase neovascularization.

It is evident that through VEGF research it has been possible to design new therapeutic strategies for the angiogenic eye disorders, as in AMD [49]. Anti-VEGF agents are currently clinically available for ocular neovascularization treatment, via intravitreal injections.

2.3. Apoptosis. Apoptosis is the programmed cell death, the cellular suicide that is essential for the normal development and survival of many organisms. Apoptosis can be classified into three distinct functional steps: induction, effector, and execution. At this moment, the affected cell undergoes an irreversible degradation of all organelle and membranes [50]. From a molecular viewpoint mitochondrial membrane increases permeability and induces the release into the 


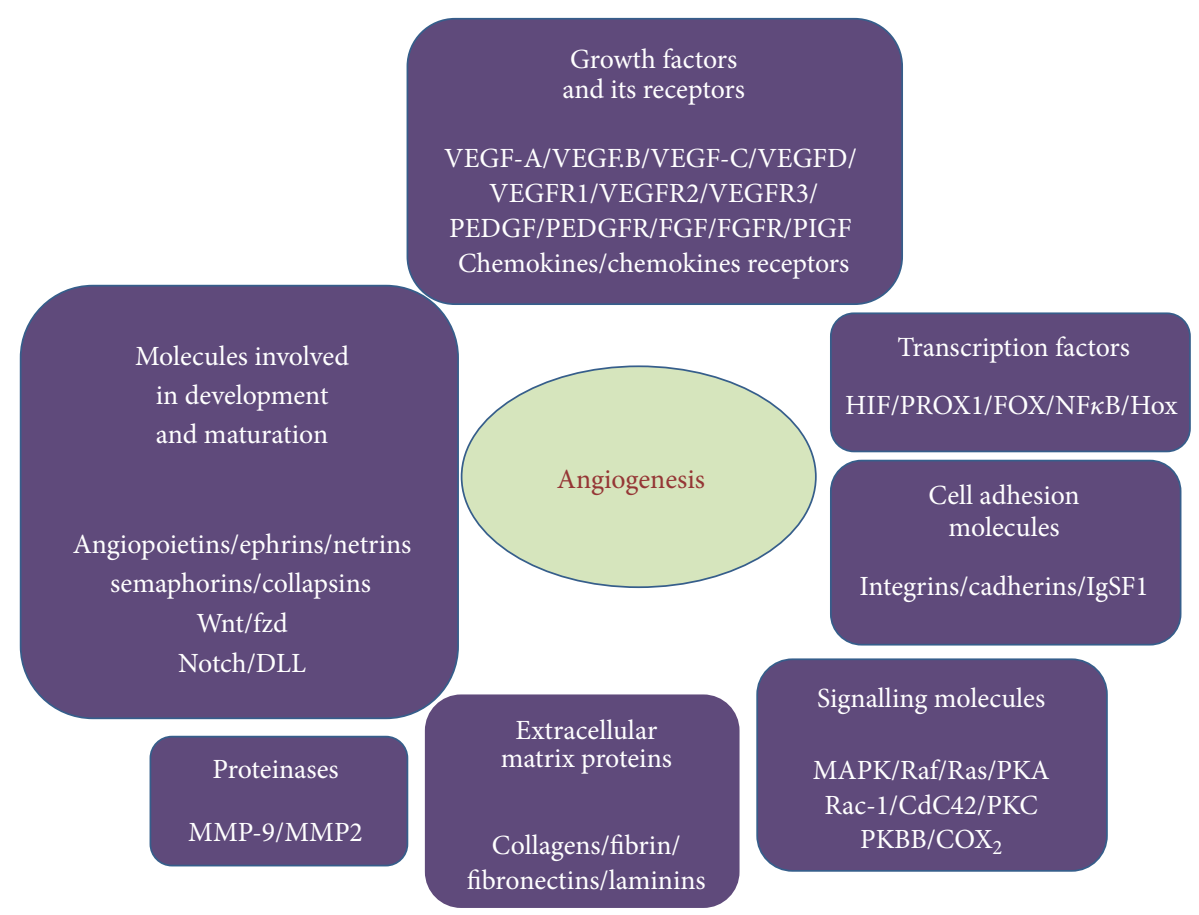

FIGURE 2: Molecules involved in angiogenesis. There are many molecules that mediate-regulate angiogenesis. The seven classes enclosed in the figure are (1) growth factors and its receptors, (2) transcription factors, (3) cell adhesion molecules, (4) signalling molecules, (5) extracellular matrix proteins, (6) proteinases, and (7) molecules involved in development and maturation. Several of these molecules have been considered for potential diagnosis or therapeutic approaches to control pathological angiogenesis.

cytosol of proapoptotic factors such as procaspases, caspase activators, and other caspase-independent factors such as the apoptosis-inducing factor, leading to cell death [51].

Experimental studies increasingly provide support that OS and apoptosis are closely linked processes and that both are implicated in the pathophysiologic mechanisms of a wide spectrum of chronic and degenerative disorders. Evidence suggests that ROS result in apoptosis of RGCs and progressive vision loss in primary open-angle glaucoma [34], as well as in AMD eyes [50-52]. Apoptosis has specifically been involved in the early outgrowth of choroidal neovascular membranes, as well as during development of fibrotic scars at later AMD stages $[39,51]$.

Recent studies demonstrated a significant increase in the terminal deoxynucleotidyl transferase dUTP nick end labelling (TUNEL)-positive cells through the retinal layering of postmortem human eyes with AMD. Moreover photoreceptors in these AMD eyes upregulate Fas, a potential mediator of apoptosis, suggesting that Fas/FasL may trigger the initiation of photoreceptor apoptosis in AMD [51].

In this scientific background it has been demonstrated that antioxidants and free radical scavengers, as well as the overexpression of the antioxidant enzyme manganese superoxide dismutase, can inhibit or delay apoptosis [53-55]. Moreover, the B cell lymphoma 2 (Bcl-2) protein has been proved to prevent cells from apoptotic death by means of an antioxidant mechanism [56]. Therefore, it has been suggested that ROS itself, and the resulting cellular redox change, can be part of the signal transduction pathways involved in apoptosis [57], as shown in Figure 3.

2.4. Inflammation. Immune-inflammatory response (IIR) attempts to rescue the organism from the cell injury and its related effects. IIR involves leukocytes/other innate immune cells and lymphocytes T, B, and NK (adaptive immunity), interacting among them by cytokines, chemokines, nitric oxide (NO), and so on [58]. Tissue damage results from uncontrolled chronic inflammation (Figure 4).

Increased inflammatory plasmatic markers such as the tumor necrosis factor-alpha, TNF alpha, sVCAM-1, Eselectin, interleukins- 6 and -18, and MCP-1 have been shown to positively correlate with age, independently of any other cardiovascular risk factors [59]. High levels of inflammatory/immune mediator molecules contribute to a proinflammatory environment that helps to develop vascular dysfunction and promotes endothelial apoptosis in aging, as suggested by Ungvari et al. in a recent review [57].

Drusen constitutes a characteristic change occurring in the macula in relation to aging and is considered an early sign of AMD. Although many authors have investigated the composition and characteristics of human drusen, further research is needed to elucidate its significance for AMD prevention. A recent review by Parmeggiani et al. [60] indicated the pathogenic role of immunologic processes in AMD occurrence, consisting of production of inflammatory related 


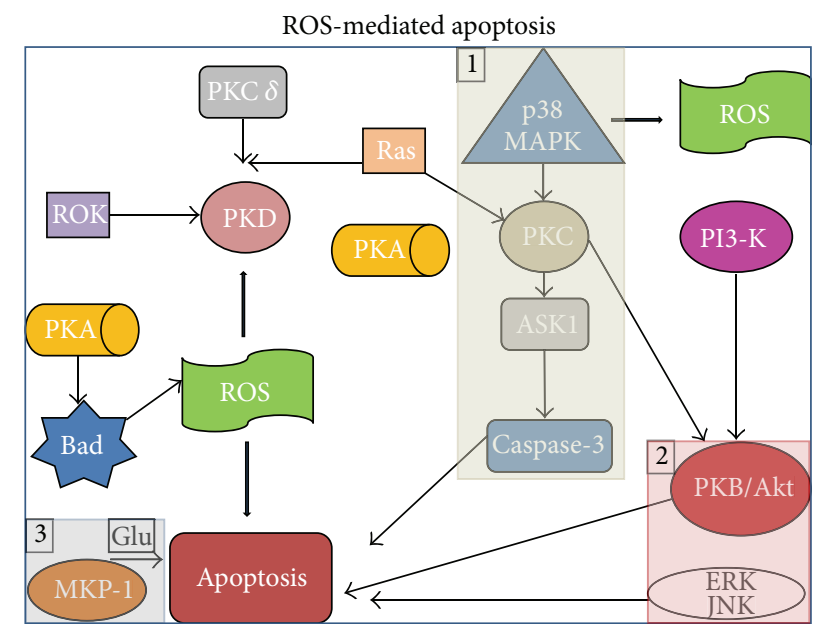

FIGURE 3: ROS-mediated apoptosis. In order to transmit physiological ROS-mediated signals and to accommodate to the OS, the cells have a wide spectrum of intracellular signal transduction systems, including protein kinase cascades. Much of these pathways are engaged in the route to apoptosis, including MAP kinases/ASK1 upstream regulator, PKB/Akt-ERK. MKP/1 and glutamate-induced cell death. Abbreviations: Akt protein kinase $\mathrm{B}(\mathrm{PKB})$, a serine/threonine-specific protein kinase; ASK1 apoptosis signal-regulating kinase 1, ERK extracellular signal-regulated kinase, Glu glutamate, JNK c-Jun NH2-terminal kinase, MAPK mitogen-activated protein kinase, MKP-1 MAPK phosphatase-1, PI3-K phosphatidylinositol 3-kinase, PKA protein kinase A, PKB protein kinase $\mathrm{B}, \mathrm{PKC}$ protein kinase $\mathrm{C}, \mathrm{PKD}$ protein kinase $\mathrm{D}, \mathrm{ROK}$ Rho kinase, and ROS reactive oxygen species.

molecules, recruitment of macrophages, complement activation, microglial activation, and accumulation within the macula. This report and other similar reports also emphasized that proteins associated with inflammation and immune response are prevalent among drusen constituents [61-63]. The authors especially focused on the importance of these new findings to improve managing of AMD patients and to prevent severe vision loss.

Altered cytokine profiles of human retinal pigment epithelium have also been related to the aging eye and AMD $[34,64]$. Moreover, oxidant injury and replicative senescence infiltration of proinflammatory $\mathrm{m} 1$ macrophages have been detected in the outer retina and precede damage in a mouse model of age-related macular degeneration [63].

Pathogenic mechanisms of AMD related to inflammation include variations in complement factor, a mayor risk factor to photo-oxidative stress and inflammation, as well as matrix metalloproteinases activity (recently described in relation to wet AMD and pro-angiogenic environment). In fact, the administration of soluble complement inhibitor Crry-Ig reduces inflammation [65].

Further research in the topic of inflammation and immune response is needed to better understand AMD and to prevent AMD-related visual disability.

\section{Expanding Our View with Studies on the Role of Antioxidants and Omega-3 Fatty Acids in AMD}

3.1. Controlled Clinical Trials. Table 1 summarizes the main publications on the effects of antioxidants and/or omega 3 PUFAS for AMD.

\subsubsection{With Positive Effects}

(1) Antioxidants. Several randomized clinical trials (RCTs) evaluated the effects of antioxidant supplements in patients with Categories 2 to 4 AMD [6, 66-70]. Some of them examined a mixture of antioxidant nutrients, including vitamin C, vitamin E, and some carotenoids such as beta-carotene or quercetin [67-70]. Other studies used zinc alone in the form of zinc sulfate $(200 \mathrm{mg} / \mathrm{d})[66,68]$ or as zinc monocysteine $(50 \mathrm{mg} / \mathrm{d})$ [69].

By far, the largest study was the multicenter AREDS trial which randomized 3640 patients with Categories 2, 3, and $4 \mathrm{AMD}$ into four treatment groups: antioxidants with carotenoids, zinc alone, antioxidants with carotenoids + zinc, or placebo [6]. The primary outcome was progression to advanced AMD (central geographic atrophy or choroidal neovascularization) and at least moderate functional visual loss, defined as the loss of $\geq 15$ letters on the ETDRS logMAR chart. A secondary visual outcome was a decrease in the best corrected visual acuity score from baseline of 30 or more letters in a study eye (six lines or a quadrupling of the initial visual angle) and progression of disease to a visual acuity score worse than 20/100 in one or both eyes. Overall, in analyses limited to only those with Category 3 or 4 AMD, a reduction in functional visual loss was noted with either supplement alone or in combination. Specifically, after five years of follow-up, the zinc/antioxidant combination significantly decreased the degree of functional vision loss (OR 0.63; 99\% CI 0.44-0.92). A similar but smaller effect was noted with either supplement alone (zinc alone OR 0.75; 99\% CI 0.53-1.07; antioxidants alone OR 0.79; 99\% CI 0.55-1.13). On the other hand, antioxidants were not associated with benefit in the large subgroup of patients with Category $2 \mathrm{AMD}(n=$ 1063) over seven years of follow-up. Of note, there was a very low rate of progression from Category $2 \mathrm{AMD}$ to more advanced disease. Of patients with Category 2 AMD at baseline, 13 progressed to advanced AMD and 316 progressed to Category 3 or 4 AMD during the study. No significant differences in demographics, socioeconomic status, smoking status, or comorbidities were noted between Category 2, 3, or 4 participants.

One additional trial found benefit from supplement use [66]. In this small trial, 90 patients with Category 3 or 4 AMD were randomized to either zinc sulfate supplements ( $200 \mathrm{mg} /$ day) or placebo. Seventy-one subjects in the placebo and 80 subjects in the zinc group completed the two-year follow-up. Most patients had Category 3 or $4 \mathrm{AMD}$ at baseline, and half the participants had baseline evidence of geographic atrophy. The placebo group was twice as likely 


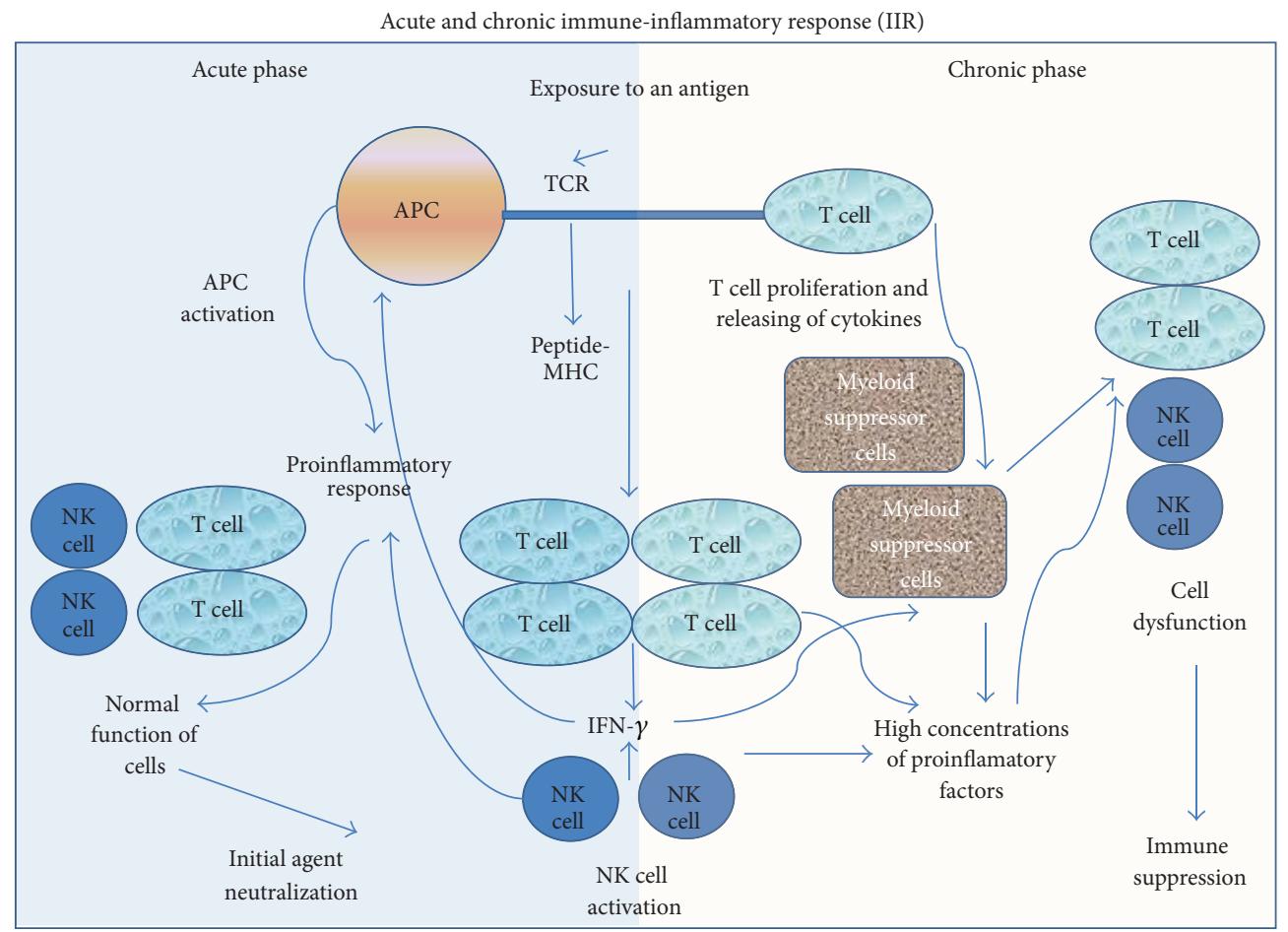

FIGURE 4: Inflammation and immune response (IIR). The primary defense mechanism of the immune system needs the activation of different cell phenotypes and intercellular signals to orchestrate all actions. Among the cytokines, the interleukines (IL) IL-1 and IL-6 and the TNFa are inducers of the IIR through the regulation of the monocytes. Immunocompetent cells are essential for an adequate immune system function, such as the macrophages, neutrophils, fibroblasts, and endothelial cells.

TABLE 1: Publications on the effects of antioxidants and/or omega 3 polyunsaturated fatty acids supplements for AMD.

\begin{tabular}{lll}
\hline Evaluation & Antioxidants & Omega 3 fatty acids \\
\hline & AREDS report 8; Arch Ophthalmol 2001 (see [6]) & \\
& AREDS2 RCT. JAMA 2005 (see [7]) & Feher et al., Ophthalmologica 2005 (see [71]) \\
& Newsome et al., Arch Ophthalmol 1988 (see [66]) & Chong et al., Arch Ophthalmol 2008 (see [72]) \\
With positive effects & Richer et al., Optometry 2004 (see [67]) & \\
& Stur et al., IOVS 1996 (see [68]) & \\
& Newsome DA. Current Eye Res 2008 (see [69]) & \\
& Richer S. J Am Optom Assoc 1996 (see [70]) & AREDS2 RCT. JAMA 2005 (see [7]) \\
& AREDS2 RCT. JAMA 2005 (see [7]) & Hodge et al., Ophthalmol 2006 (see [80]) \\
& Leeuwen et al., JAMA 2005 (see [74]) & Chong et al., BMJ 2007 (see [81]) \\
& Flood et al., Ophthalmology 2002 (see [75]) & Soused et al., Ophthalmology 2013 (see [82]) \\
& Chow et al., Arch Ophthalmol 2004 (see [76]) & Heinonen et al., Annals of Epidemiology 2004 \\
& Van den Langenberg et al., Am J Epidemiol 1998 (see [77]) & (see [84]) \\
& Taylor et al., BMJ 2002 (see [79]) & Tan et al., Ophthalmology 2008 (see [87]) \\
Without effects & Moeller et al., Arch Ophthalmol 2006 (see [78]) & Olson et al., Semin Ophthalmol 2011 (see [88]) \\
& Teikari et al., Acta Ophthalmol Scand. 1998 (see [83]) & \\
& Omenn et al., N Engl J Med 1996 (see [86]) & \\
& AREDS report 8; Arch Ophthalmol 2001 (see [6]) & \\
& AREDS2 RCT. JAMA. 2013 (see [7]) & AREDS2 RCT. JAMA 2005 (see [7]) \\
& The ATBC Cancer Prevention Study Group. Ann & \\
& Epidemiol 1994 (see [84]) \\
& Goodman GE et al., Cancer Epidemiol Biomarkers Prev & \\
1993 (see [85]) & Omenn et al., N Engl J Med 1996 (see [86]) & \\
\hline
\end{tabular}


as the zinc- supplemented group to demonstrate clinically significant vision loss (15.5\% versus $7.5 \%)$.

Other studies were small ( $n=56$ or less), of relatively short duration (6 to 24 months), and did not report a clinically significant reduction in visual loss from supplement use. [67-69]. Two of these trials were conducted in VA settings.

One randomized trial reported the effects of a supplemental carotenoid, lutein $(10 \mathrm{mg} / \mathrm{d})$, among subjects with AMD [67]. Subjects were randomized to lutein alone $(n=$ 29 ), lutein + antioxidants (OcuPower; $n=30$ ), or placebo $(n=31)$ for 12 months. The authors report very small increases in visual acuity in the lutein and lutein + antioxidants groups, but these changes were not clinically significant $(<15$ letters) after a one-year follow-up.

Another small, multicenter VA trial evaluated the effects of a tablet containing a number of antioxidants and, similarly, found nonclinically significant improvement in visual acuity [70].

(2) Omega-3 Fatty Acids. One study examined the effects of supplemental omega-3 fatty acids, L-carnitine, and coenzyme Q10 among subjects with AMD [71]. Most (93.6\%) subjects in this study had "early" AMD at baseline; only 6.4 percent had Category 3 or 4 AMD. The study randomized subjects to omega-3 fatty acid supplement $(n=52)$ or placebo $(n=55)$. The change in visual acuity was measured after 12 months of supplementation. The report noted that omega- 3 fatty acids slowed visual acuity loss but not to a clinically significant degree (0.5 line change in Snellen acuity). Other studies analysed the role of dietary omega-3 PUFAS and fish intake in the primary prevention of AMD [72]. Christen et al. [73] in a large cohort of female health professionals who were free of a diagnosis of AMD at baseline, examined the relation of dietary intake of DHA/EPA and fish with visually significant AMD during 10 years of follow-up. Results from this study demonstrated that regular consumption of DHA and EPA and fish was associated with a significantly decreased risk of incident AMD. Authors suggested that this intervention may benefit primary prevention of AMD.

AREDS2. The National Institute of Health (NIH) commissioned the National Eye Institute to conduct the Age-Related Eye Disease Study 2 (AREDS2) [7]. It was a multicentered, randomized, double-masked, placebo-controlled phase 3 study with a $2 \times 2$ factorial design, conducted in 2006 to 2012 and enrolling 4203 participants aged 50 to 85 years at risk of progression to advanced AMD with bilateral large drusen or large drusen in one eye and advanced AMD in the fellow eye. The purpose of the study was to determine whether adding lutein + zeaxanthin, DHA + EPA, or both to the AREDS formulation decreases the risk of developing advanced AMD. Additionally, the treatment arms evaluated the effects of eliminating beta-carotene from the original AREDS formulation of antioxidants (500 mg vitamin C; $400 \mathrm{IU}$ vitamin E; and $15 \mathrm{mg}$ beta-carotene) and/or lowering the zinc component of the supplement (previously $80 \mathrm{mg}$ zinc as zinc oxide, and $2 \mathrm{mg}$ copper as cupric oxide). Participants were randomized to receive lutein $(10 \mathrm{mg})+$ zeaxanthin $(2 \mathrm{mg})$, DHA (350 mg) + EPA (650 mg), lutein + zeaxanthin and DHA + EPA, or placebo. All participants were also asked to take the original AREDS formulation or accept a secondary randomization to 4 variations of the AREDS formulation, including elimination of beta-carotene, lowering of zinc dose, or both. After a median follow-up of 5 years, 1940 study eyes (1608 participants) progressed to advanced AMD. KaplanMeier probabilities of progression to advanced AMD by 5 years were $31 \%$ for placebo, $29 \%$ for lutein + zeaxanthin, $31 \%$ for DHA + EPA, and 30\% for lutein + zeaxanthin and DHA + EPA. Comparison with placebo in the primary analyses demonstrated no statistically significant reduction in the progression to advanced AMD (hazard ratio [HR], 0.90 [98.7\% CI, 0.76-1.07]; $P=.12$ for lutein + zeaxanthin; 0.97 [98.7\% CI, 0.82-1.16]; $P=.70$ for DHA + EPA; 0.89 [98.7\% CI, 0.75-1.06]; $P=.10$ for lutein + zeaxanthin and DHA + EPA). There was no apparent effect of beta-carotene elimination or lower-dose zinc on progression to advanced AMD. More lung cancers were noted in the beta-carotene versus no beta-carotene group [2.0\%] versus 11 [0.9\%], $P=.04$, mostly in former smokers.

The study concluded that addition of lutein + zeaxanthin, DHA + EPA, or both to the original AREDS formulation in primary analyses did not further reduce risk of progression to advanced AMD. However, because of potential increased incidence of lung cancer in former smokers, lutein + zeaxanthin could be an appropriate carotenoid substitute in the AREDS formulation.

\subsubsection{Without Effects}

(1) Antioxidants. Antioxidants have been hypothesised to reduce oxidative damage to the retina, but the effectiveness of dietary oxidants in the primary prevention of AMD is unclear.

Previous studies and reviews have largely focused on the role of dietary antioxidants and supplements in the prevention of early AMD or progression to late AMD in people with signs of early disease. Among all the clinical trials done, most of them are prospective cohort studies. Only four are randomized clinical trials (including the AREDS2, recently released).

All the studies dealing with the role of antioxidants and supplements found that there is little or no effect of vitamins (A, C, and E) zinc, lutein, zeaxanthin, other carotenoids, and omega-3 fatty acids [73] to prevent AMD.

Dietary Antioxidants and Early AMD. Vitamin A: the studies that contributed to the pooled analysis reported null associations between intake of vitamin $\mathrm{A}$ and prevention of AMD [74-76].

Vitamin C: due to the heterogeneity of the studies, there are reported positive associations [77] as well as inverse [76] or null effect in preventing AMD [74-76].

Vitamin E: most of the cohort and randomized studies published have reported null or inverse association between intake and preventing AMD $[74,77,78]$. In randomized trials, no protective effect was seen for vitamin $\mathrm{E}$. 
TABLE 2: RCTs: Beta-carotene and risk of lung cancer in smokers.

\begin{tabular}{|c|c|c|c|c|c|}
\hline $\begin{array}{l}\text { Randomized clinical trials } \\
\text { (RCTs) }\end{array}$ & $N$ & Treatment groups & Follow-up & Lung cancer risk (smokers) & $P$ value \\
\hline $\begin{array}{l}\text { The Alpha-Tocopherol, } \\
\text { Beta-Carotene (ATBC) Lung } \\
\text { Cancer Prevention } \\
\text { Study-1985-1993 (see [84]) }\end{array}$ & $\begin{array}{l}29133 \text { smokers } \\
\text { (men) }\end{array}$ & $\begin{array}{l}\text { Group 1: } \alpha \text {-tocoferol } \\
\text { Group 2: } \beta \text {-carotene } \\
\text { Group 3: Placebo }\end{array}$ & $5-8$ years & $\begin{array}{l}\text { Beta-Carotene } \\
\text { supplementation was } \\
\text { associated with increased } \\
\text { lung cancer risk }(\mathrm{RR}=1.16 \text {; } \\
95 \% \mathrm{CI}=1.02-1.33)\end{array}$ & $P=.02$ \\
\hline $\begin{array}{l}\text { The carotene and retinol efficacy } \\
\text { trial (CARET)-1993 (see [85]) }\end{array}$ & $\begin{array}{l}18314 \text { smokers } \\
\text { (men and } \\
\text { women) or } \\
\text { asbestos } \\
\text { exposed }\end{array}$ & $\begin{array}{l}\text { Group 1: } \beta \text {-carotene and } \\
\text { retinyl palmitate } \\
\text { Group 2: Placebo }\end{array}$ & $\begin{array}{l}\text { Stopped } 21 \\
\text { months } \\
\text { earlier }\end{array}$ & $\begin{array}{l}\text { There were } 28 \% \text { more lung } \\
\text { cancers and } 17 \% \text { more } \\
\text { deaths in the active } \\
\text { intervention group }\end{array}$ & $P=.01$ \\
\hline
\end{tabular}

Zinc: results are contradictory. Most of them reported positive associations except one null [77] and other inverse association [74].

Lutein and zeaxanthin: none of the findings in the studies were statistically significant, most of them showed null [78, 79] or even inverse correlation between their supplementation and prevention of progression of AMD [76]. The AREDS2 [7] found no benefit in the addition of lutein plus zeaxanthin to the AREDS formulation to reduce risk of AMD progression.

Omega-3 fatty acids: although few prospective studies and meta-analysis suggest that the consumption of fish and foods rich in omega-3 fatty acids may be associated with low risk of $\mathrm{AMD}$, there is insufficient evidence to support their routine consumption for AMD prevention [80-82]. Only one randomized clinical trial (AREDS2) concluded that DHA plus EPA added to the AREDS formulation did not further reduce the risk of progression to advanced AMD [78].

Dietary Antioxidants and Late AMD. Only few published cohort studies provided data for risk of late AMD. Each of them evaluated different antioxidants. There is insufficient evidence that antioxidants at the studied doses prevent the progression to late AMD $[83,84]$.

3.1.3. With Adverse Effects. Treatment options for nonneovascular Age Macular Degeneration (AMD) are limited and no prophylaxis is still available. Several randomized clinical trials (RCTs) have been done during the last two decades based on the beneficial effects of antioxidants, vitamins, and zinc. The benefits of these micronutrients have been demonstrated but although generally reported as safe, vitamin supplements may also have harmful effects.

More than thirty large RCTs with more than one year of follow-up have been registered to study the efficacy and safety of oral supplements. The evidence for harms has been driven by two trials, the Alpha-Tocopherol, Beta-Carotene (ATBC) Lung Cancer Prevention Study, and the Carotene and Retinol Efficacy Trial (CARET) [84-87]. Vitamin E at high doses seemed to be associated with increased risk of mortality, congestive heart failure, prostate cancer, and betacarotene with an increased risk of lung cancer among active smokers (Table 2).
The Age-Related Eye Disease Study (AREDS) [6], a multicentered, prospective, randomized trial sponsored by the National Eye Institute of Health, was designed to assess the clinical course of AMD and to evaluate the effect of high doses of vitamin C, vitamin E, beta-carotene, and zinc on the progression of this disease. In 2001 the results were published [6]. From the efficacy point of view a reduced risk of advanced age-related macular degeneration and vision loss for study participants with some degree of AMD who were assigned to high-dose supplementation with antioxidants plus zinc was reported. Regarding safety, circulatory adverse effects were more frequently found in the zinc groups $(P=.01)$ as well as genitourinary hospitalizations $(P=.001)$ and hospitalizations for mild/moderate symptoms $(P=.04)$. Skin and subcutaneous tissue conditions (yellow skin) were more frequent in the antioxidant arms $(P=.003)$. Although the risk of lung cancer among smokers was not established in this study, the data and safety monitoring committee recommended that smokers should discontinue study medications containing beta-carotene based on the results from the RTCs that had suggested increased risk of mortality among smokers supplemented with beta-carotene [84-86].

Beta-carotene intake also seems to predict neovascular AMD in both smoker and nonsmokers and higher intakes of total vitamin E predict late AMD as it was shown in the Blue Mountain study [87]. On the other side, several studies with lutein, zeaxanthin, vitamins, and omega-3 fatty acids have been reported to decrease AMD progression [88] Omega3 long-chain polyunsaturated fatty acids have been recently mentioned to have a potential benefit in patients with AMD or those at risk of AMD, and although several studies have demonstrated that high dietary intake of omega-3 fatty acids is associated with a $38 \%$ decreased risk for late AMD, there are not many RCTs with this micronutrient [71-73].

The AREDS 2 [7], a multicentered, randomized, controlled phase 3 clinical trial with a $2 \times 2$ factorial design, conducted between 2006 and 2012 and enrolling 4203 participants aged 50 to 85 years at risk of progression to advanced AMD was designed to determine whether adding lutein + zeaxanthin, DHA + EPA, or both to the initial AREDS formulation decreases the risk of developing advanced AMD. The results have been recently published. The addition of lutein + zeaxanthin, DHA + EPA, or both to the AREDS formulation 
TABLE 3: Summary of different animal models studied in relation to dietary omega-3 PUFA.

\begin{tabular}{lcl}
\hline Authors & Animal model & Results \\
\hline Koto T et al., 2007 (see [92]) & C57BL/6 mice & $\begin{array}{l}\text { Supplementation with EPA prevented choroidal } \\
\text { neovascularization induced after laser photocoagulation }\end{array}$ \\
\hline Chan et al., 2008 (see [94]) & Cx3crl and Ccl2-deficient mice & $\begin{array}{l}\text { Smaller number of retinal lesions when diet high in omega-3 } \\
\text { PUFA }\end{array}$ \\
\hline Tuo et al., 2009 (see [93]) & Cx3crl and Ccl2-deficient mice & $\begin{array}{l}\text { Mice that ingested a high omega-3 PUFA diet showed a } \\
\text { slower progression of retinal lesions compared with the low } \\
\text { omega-3 PUFA group }\end{array}$ \\
$\begin{array}{l}\text { Neuringer et al., 2010 (see [100]) } \\
\text { Renner et al., 2013 (see [102]) }\end{array}$ & Macaque monkeys & $\begin{array}{l}\text { Diets lacking carotenoids and omega-3 PUFAs developed } \\
\text { patches of RPE atrophy and increased incidence of drusen. } \\
\text { SD-OCT showed RPE disruption }\end{array}$ \\
\hline
\end{tabular}

do not reduce risk of progression to advanced AMD and regarding safety, more lung cancers were noted in the betacarotene versus no beta-carotene group (2.0\% versus $110.9 \%$, $P=.04)$, mostly in former smokers [7]. It is known that the elevated zinc concentration used in AREDS causes minor side effects, such as stomach problems. Copper, as cupric oxide, was added to avoid anemia induced by high zinc intake. Moreover, it was stated from ARED2 results that while zinc is an important component of the formulation, it is now unclear how much zinc is necessary for the purpose of the study.

With the megadoses of vitamins and minerals that have been utilized by different studies, it has to be taken into consideration that secondary effects can appear. In fact, vitamin E appropriate dosage can be confusing. However, current guidelines [89] instructed about dietary allowances (RDA) and upper tolerable threshold for vitamins. But, it is usually seen that most commercial products remain labeled in International Units (IUs), instead of $\mathrm{mg}$, as recommended. Vitamin E supplementation may potentiate the effects of Warfarin (Coumadin). Therefore, taking vitamin $\mathrm{E}$ along with the latter can increase the chances of bleeding. Vitamin E supplementation has been associated with increased risk of heart failure. Taking into account all the above information, summarized in Table 1, and although valuable clinical effects of nutritional supplements have been reported, more information about safety in the general population is needed.

3.2. Animal Models for AMD and the Effects of Antioxidants Omega-3 PUFA. As shown above some clinical trials have suggested that omega-3 polyunsaturated fatty acids (omega3 PUFA) decrease the likelihood of developing AMD. Some animal models have also been developed in order to check this hypothesis, mainly in rodents and primates (Table 3).

Mammals depend on dietary intake of omega-3 PUFA, because mammalian cells lack enzymes necessary to synthesize the precursor of omega-3 PUFA and to convert omega6 to omega-3 PUFA $[86,90]$. Sufficient omega-3 PUFA are principally derived from fish and seafood and are difficult to obtain from purely vegetarian sources. The animal models have been tested with high or low dietary intake of omega3 PUFA.
On the one hand, the use of murine models can provide basic physiology and pathology relevant to human AMD, because they are relatively cheap and easily reproduced and manipulated. However, rodents have no macula and their retinal photoreceptor cells are predominantly rods, rather than the cone cells that predominate in the human macula. What cones the rats do have are dispersed throughout the retina, rather than concentrated around the fovea as they are in humans [91].

In one study, four-week supplementation with 5\% EPA was shown to prevent choroidal neovascularization induced after laser photocoagulation in 6-week-old C57BL/6 mice [92]. EPA also exerted anti-inflammatory action locally in the eye, as well as systemically in the circulation by means of significant reduction in the expression and production of inflammatory and angiogenic markers in the RPE, endothelial cells, and macrophages, and lower serum CRP and IL-6.

$\mathrm{Cx} 3 \mathrm{crl}$ and $\mathrm{Ccl} 2$-deficient mice (double-knockout) have been shown to present a synergistic effect resulting in a phenotype displaying typical AMD features with early onset and high penetrance $[93,94]$. A diet enriched in DHA and EPA for 12 weeks in 9 -week-old $\mathrm{Ccl} 2 / \mathrm{Cx} 3 \mathrm{crl}$ deficient mice can ameliorate the progression of retinal lesions such as retinal and subretinal spots, chorioretinal scars, focal loss of photoreceptors, and focal hypopigmentation of the RPE cells. The authors proposed the increase of anti-inflammatory derivatives such as PGD2 and the decrease of proinflammatory derivatives such as PGE2, LTB2, TNF-alpha, and IL-6 as the mechanisms underlying the lower disease progression $[94,95]$.

On the other hand, nonhuman primates offer the closest anatomy to humans, but are quite difficult to manipulate genetically, costly to maintain, have a slow time course of disease progression, and some researchers are also loath to conduct research in primates for ethical reasons [90, 91]. Macaque monkeys have a macula and commonly develop age-related maculopathy that shares common features and risk factors with human AMD. Monkeys rarely show spontaneous development of either the wet or dry form of advanced AMD, but it has been documented the signs of early to intermediate AMD in older rhesus macaque monkeys (Macaca mulatta) $[96,97]$. 
However, there is one monkey model of cynomolgus macques (Macaca fascicularis) that presents an early-onset macular degeneration syndrome $[98,99]$. Besides, a similar syndrome has been identified in the Japanese macaque (Macaca fuscata) [100].

Human and monkey drusen has been shown to be histopathologically similar [101]. Furthermore, it appears that both species present similar key nutritional risk factors for AMD development. Monkey-fed-diets lacking luteinzeaxanthin and omega-3 PUFA showed an increased incidence of drusen at early ages, by 15 years of age (equivalent to 45 human years), and atrophic macular disease [99, 101, 102]. Moreover, adequate intake of omega-3 PUFA reduces the blue-light-induced damage in the parafovea of rhesus monkeys [103]. A summary of these data is enclosed in Table 2.

All these findings provide support for the role of omega-3 PUFA as an important factor in the development of AMD in animal models.

\subsection{In Vitro Models for AMD and Evaluation of Antioxidants} and Omega-3 Fatty Acids. Due to its high complexity it is not easy to find in vitro models that mimic AMD, mainly for three reasons: the first one and the most important is due to the unawareness of the etiology and physiology of AMD; the second one is as a matter of the complexity of the disease involving a variety of cell types; and the last one but not the least refers to the variety of disease types and findings (exudative AMD, atrophy, drusen, and pigment abnormalities).

3.3.1. In Vitro Models of Angiogenesis. Choroidal neovascularization and VEGF play an essential role on exudative AMD.

Endothelial primary cultures are the most useful cell types used for this purpose, as they are the main constituent of blood vessels and its proliferation and migration induced by VEGF play an essential role in the pathologic angiogenesis.

Studies using bovine carotid endothelial cells are described [103], in which the effects of EPA on VEGFinduced MAP kinase activation are tested, as well as the expression of VEGF receptors. The use of primary culture of human umbilical vein endothelial cells (HUVECs) is also considered as a good model for the understanding of the pathology [104]. A study evaluating the antiangiogenic properties of EPA on proliferation, migration, and tube formation of HUVEC cultures has been published with promising results [105]. The use of human aortic endothelial cells [105] is another alternative. Finally, the most useful cell type for the study and the understanding of proliferative eye pathologies might be the retinal microvascular endothelial cells, mostly extracted from bovine [106] or porcine [107] eyes, although PUFAs antiangiogenic properties have not been tested yet on it.

3.3.2. In Vitro Models of Oxidative Stress. Although the mechanisms involved in AMD are still not completely understood, it is well known that oxidative stress plays a major role in the evolution of this pathology. Cells undergoing oxidative stress produce proinflammatory and proangiogenic factors and they are more susceptible to apoptosis.

The classical way to produce oxidative stress is the reduction of the oxygen concentration in the environment. The hypoxia/reoxygenation model in HUVEC cultures [108] shows an increased production of reactive oxygen species and a dysfunction in gap junctions, which is reversed by EPA pretreatment.

Another good approach to mimic the oxidative stress produced in the retina is the use of oxidant agents. One of the most extended methods is the addition of $\mathrm{H}_{2} \mathrm{O}_{2}$ in the cultures. This approach has been used to demonstrate the protective effect of DHA derivative neuroprotectin D1 in ARPE-19 cells (a spontaneously transformed human RPE cell line), showing DNA fragmentation reduction, caspase cleavage reduction, and upregulation of antiapoptotic proteins [109]. The difficulty of this technique lies in conveniently diluting $\mathrm{H}_{2} \mathrm{O}_{2}$ to generate stress without causing widespread cell death. Other oxidant agents can also be used to generate stress, for example, paraquad [110]. In this study they isolate neuronal cultures from rat retinas and expose them to the oxidant, testing the protective properties of DHA and macular carotenoids. The cell viability, apoptosis, and the mitochondrial membrane potential are evaluated. Finally, tert-butyl hydroperoxide $(\mathrm{tBH})$ has also been demonstrated to cause an oxidative stress in vitro in ARPE-19 cultures [111], and it has been used in the study of the efficacy of various antioxidants protecting the retinal pigment epithelium from oxidative stress [112-114], although PUFAs protection has not been tested in this model yet.

The last model of oxidative stress is the light stress model [115] based on in vitro liposomal membranes reproduction mimicking the macular membranes of human retina, and posterior UV radiation to produce oxidative damage. This model has only been used to test the effect of lutein and zeaxanthin on lipid oxidation, but this might be also a promising tool for the research of antioxidant properties of PUFAs.

\section{Conclusions and Future Directions}

The AMD is a leading promoter of visual disability in people over their sixties, with an exponentially growing prevalence that continues to rise. The AMD pathogenesis involves a complex interaction of cellular and molecular factors, which may be induced by light damage, OS, angiogenesis, apoptosis, and/or inflammation. In this context, it is evident that nutrients and other dietary components may contribute to AMD. Although new treatments for AMD have appeared in the past years, which have notably improved visual outcomes and quality of life, disappointing clinical results are still present in the clinical practice. Therefore, knowledge on the pathogenic mechanisms of AMD remains far from complete. With a simple view to reduce OS, apoptosis, inflammation, and/or angiogenesis, the role of nutritional antioxidant supplements and omega-3 PUFAs on the initiation and progression of 
AMD are currently unresolved. However, wide circumstantial evidences from epidemiological studies and preclinical "in vivo" and "in vitro" research are strongly supportive.

Many observational studies have suggested a benefit from high dietary intakes of omega-3 and macular pigments like lutein and zeaxanthin which are associated with a lower risk of prevalence and incidence in AMD. However, in the case of omega-3 more clinical trials are required for concrete recommendations on their use. The Age-Related Eye Disease study (AREDS) showed a beneficial effect of high doses of vitamins $\mathrm{C}, \mathrm{E}$, beta-carotene, and zinc with copper in reducing the risk of progression to advanced AMD in patients with intermediate AMD or in patients with one-sided late AMD. The AREDS-2 study has shown that lutein and zeaxanthin may substitute beta-carotene because of potential increased incidence of lung cancer. For summarizing the effects of antioxidants and $w-3$ fatty acids see Table 1 .

In Europe, the doses of vitamins and minerals used in addition to lutein and omega-3 are typically lower than the doses used in the two AREDS studies and in other larger observational studies. In addition, dietary habits, environmental factors, medical conditions, lifestyles, and genetic background are different in the European countries from the population involved in the AREDS. In that scenario, there are no data about the protective effect of these nutritional supplements on the secondary prevention of AMD. So, Europeanbased study would be very helpful to determine the effect of nutritional supplements in AMD prevention.

In the near future new devices and new designs will improve the diagnostic and therapeutic options for AMD at different stages with the challenge of personalizing the patient management and standards of care.

\section{Disclosure}

This paper has not been previously published by the authors. All authors concur with the submission.

\section{Conflict of Interests}

The authors declare that there is no conflict of interests regarding the publication of this paper.

\section{References}

[1] G. Soubrane, A. Cruess, A. Lotery et al., "Burden and health care resource utilization in neovascular age-related macular degeneration: findings of a multicountry study," Archives of Ophthalmology, vol. 125, no. 9, pp. 1249-1254, 2007.

[2] J. W. Miller, "Age-related macular degeneration revisitedpiecing the puzzle: the LXIX Edward Jackson memorial lecture," The American Journal of Ophthalmology, vol. 155, pp. 1-35, 2013.

[3] T. Lin, G. B. Walker, K. Kurji et al., "Parainflammation associated with advanced glycation endproduct stimulation of RPE in vitro: implications for age-related degenerative diseases of the eye," Cytokine, vol. 62, pp. 369-381, 2013.

[4] A. Swaroop, E. Y. Chew, C. B. Rickman, and G. R. Abecasis, "Unraveling a multifactorial late-onset disease: from genetic susceptibility to disease mechanisms for age-related macular degeneration," Annual Review of Genomics and Human Genetics, vol. 10, pp. 19-43, 2009.

[5] T. Aslam, C. Delcourt, R. Silva et al., "Micronutrients in agerelated macular degeneration," Ophthalmologica, vol. 229, pp. 75-79, 2012.

[6] Age-Related Eye Disease Study Research Group, "A randomized, placebo-controled clinical trial of high-dose supplementation with vitamins $\mathrm{C}$ and $\mathrm{E}$, beta carotene and zinc for agerelated macular degeneration and visual loss: AREDS report 8," Archives of Ophthalmology, vol. 119, pp. 1417-1436, 2001.

[7] Age-Related Eye Disease Study 2 Research Group, "Lutein + zeaxanthin and omega-3 fatty acids for age-related macular degeneration: the Age-Related Eye Disease Study 2 (AREDS2) randomized clinical trial," The Journal of the American Medical Association, vol. 309, pp. 2005-2015, 2013.

[8] I. Fridovich, "The biology of oxygen radicals. The superoxide radical is an agent of oxygen toxicity: superoxide dismutases provide an important defense," Science, vol. 201, no. 4359, pp. 875-880, 1978.

[9] B. Halliwell, "Free radicals and antioxidants: updating a personal view," Nutrition Reviews, vol. 70, no. 5, pp. 257-265, 2012.

[10] W. A. Pryor, "Free radicals and lipid peroxidation: what they are and how theygot that way," in Natural Antioxidants in Human Health and Disease, B. Frei, Ed., pp. 1-24, Academic Press, San Diego, Calif, USA, 1994.

[11] N. Acar, S. Gregoire, A. Andre et al., "Plasmalogens in the retina: in situ hybridization of dihydroxyacetone phosphate acyltransferase (DHAP-AT) - the first enzyme involved in their biosynthesis-and comparative study of retinal and retinal pigment epithelial lipid composition," Experimental Eye Research, vol. 84, no. 1, pp. 143-151, 2007.

[12] N. Acar, O. Berdeaux, S. Grégoire et al., "Lipid composition of the human eye: are red blood cells a good mirror of retinal and optic nerve fatty acids?" PLOS ONE, vol. 7, no. 4, Article ID e35102, 2012.

[13] R. T. Holman, L. Smythe, and S. Johnson, "Effect of sex and age on fatty acid composition of human serum lipids," The American Journal of Clinical Nutrition, vol. 32, no. 12, pp. 2390-2399, 1979.

[14] J. C. Khan, H. Shahid, D. A. Thurlby et al., "Age related macular degeneration and sun exposure, iris colour, and skin sensitivity to sunlight," The British Journal of Ophthalmology, vol. 90, no. 1, pp. 29-32, 2006.

[15] W. Smith, J. Assink, R. Klein et al., "Risk factors for age-related macular degeneration: pooled findings from three continents," Ophthalmology, vol. 108, no. 4, pp. 697-704, 2001.

[16] R. Klein, B. E. Klein, S. C. Jensen, J. A. Mares-Perlman, K. J. Cruickshanks, and M. Palta, "Age-related maculopathy in a multiracial United States population: the National Health and Nutrition Examination Survey III," Ophthalmology, vol. 106, no. 6, pp. 1056-1065, 1999.

[17] R. Varma, S. Fraser-Bell, S. Tan, R. Klein, S. P. Azen, and Los Angeles Latino Eye Study Group, "Prevalence of age-related macular degeneration in Latinos: the Los Angeles Latino eye study," Ophthalmology, vol. 111, no. 7, pp. 1288-1297, 2004.

[18] M. A. Zarbin, "Current concepts in the pathogenesis of agerelated macular degeneration," Archives of Ophthalmology, vol. 122, no. 4, pp. 598-614, 2004.

[19] N. I. Krinsky, J. T. Landrum, and R. A. Bone, "Biologic mechanisms of the protective role of lutein and zeaxanthin in the eye," Annual Review of Nutrition, vol. 23, pp. 171-201, 2003. 
[20] D. Pauleikhoff, F. J. van Kuijk, and A. C. Bird, "Macular pigment and age-related macular degeneration," Ophthalmologe, vol. 98, no. 6, pp. 511-519, 2001.

[21] J. Wu, S. Seregard, and P. V. Algvere, "Photochemical damage of the retina," Survey of Ophthalmology, vol. 51, no. 5, pp. 461-481, 2006.

[22] P. V. Algvere, J. Marshall, and S. Seregard, "Age-related maculopathy and the impact of blue light hazard," Acta Ophthalmologica Scandinavica, vol. 84, no. 1, pp. 4-15, 2006.

[23] T. H. Margrain, M. Boulton, J. Marshall, and D. H. Sliney, "Do blue light filters confer protection against age-related macular degeneration?" Progress in Retinal and Eye Research, vol. 23, no. 5, pp. 523-531, 2004.

[24] R. Klein, B. E. Klein, S. C. Jensen, and K. J. Cruickshanks, "Sunlight and the 5-year incidence of early age-related maculopathy: the Beaver Dam Eye Study," Archives of Ophthalmology, vol. 119, pp. 246-250, 2001.

[25] L. Biasutto, A. Chiechi, R. Couch, L. A. Liotta, and V. Espina, "The RPE exosomes contain signaling phosphoproteins affected by oxidative stress," Experimental Cell Research, vol. 119, pp. 2113-2123, 2013.

[26] S. Beatty, H. Koh, M. Phil, D. Henson, and M. Boulton, "The role of oxidative stress in the pathogenesis of age-related macular degeneration," Survey of Ophthalmology, vol. 45, no. 2, pp. 115134,2000

[27] P. C. Calder, "Polyunsaturated fatty acids, inflammation, and immunity," Lipids, vol. 36, no. 9, pp. 1007-1024, 2001.

[28] P. K. Mukherjee, V. L. Marcheselli, J. C. de Rivero Vaccari, W. C. Gordon, F. E. Jackson, and N. G. Bazan, "Photoreceptor outer segment phagocytosis attenuates oxidative stress-induced apoptosis with concomitant neuroprotectin D1 synthesis," Proceedings of the National Academy of Sciences of the United States of America, vol. 104, no. 32, pp. 13158-13163, 2007.

[29] M. D. Pinazo-Durán and L. Boscá-Gomar, "Anti-inflammatory properties of polyunsaturated fatty acid omega 3," Indications in Ophthalmology, vol. 87, pp. 203-205, 2012.

[30] J. Blasiak, S. Glowacki, A. Kauppinen, and K. Kaarniranta, "Mitochondrial and nuclear DNA damage and repair in agerelated macular degeneration," International Journal of Molecular, vol. 14, no. 2, pp. 2996-3010, 2013.

[31] E. Synowiec, T. Sliwinski, K. Danisz et al., "Association between polymorphism of the NQO1, NOS3 and NFE2L2 genes and AMD," Frontiers in Bioscience, vol. 18, pp. 80-90, 2013.

[32] M. C. Kenney, D. Hertzog, G. Chak et al., "Mitochondrial DNA haplogroups confer differences in risk for age-related macular degeneration: a case control study," BMC Medical Genetics, vol. 14, article 4, 2013.

[33] T. U. Krohne, N. K. Stratmann, J. Kopitz, and F. G. Holz, "Effects of lipid peroxidation products on lipofuscinogenesis and autophagy in human retinal pigment epithelial cells," Experimental Eye Research, vol. 90, no. 3, pp. 465-471, 2010.

[34] M. D. Pinazo-Durán, V. Zanón-Moreno, J. J. García-Medina, and R. Gallego-Pinazo, "Evaluation of presumptive biomarkers of oxidative stress, immune response and apoptosis in primary open-angle glaucoma," Current Opinion in Pharmacology, vol. 13, pp. 98-107, 2013.

[35] R. Dănulescu and D. Costin, "Use of blood markers in early diagnosis of oxidative stress in age related macular degeneration," Revista Medico-Chirurgicala a Societatii de Medici si Naturalisti din Iasi, vol. 116, no. 4, pp. 1136-1142, 2012.
[36] J. Yao, X. Liu, Q. Yang et al., "Proteomic analysis of the aqueous humor in patients with wet age-related macular degeneration," Proteomics Clinical Applications, vol. 7, no. 550, pp. 7-860, 2013.

[37] R. T. Libby and D. B. Gould, "Endoplasmic reticulum stress as a primary pathogenic mechanism leading to age-related macular degeneration," Advances in Experimental Medicine and Biology, vol. 664, pp. 403-409, 2010.

[38] G. Rodríguez Diez, S. Sánchez Campos, N. M. Giusto, and G. A. Salvador, "Specific roles for Group V secretory PLA $\mathrm{PL}_{2}$ in retinal iron-induced oxidative stress. Implications for age-related macular degeneration," Experimental Eye Research, vol. 113, pp. 172-181, 2013.

[39] V. Nikoletopoulou, M. Markaki, K. Palikaras, and N. Tavernarakis, "Crosstalk between apoptosis, necrosis and autophagy," Biochimica et Biophysica Acta, vol. 1833, no. 12, pp. 34483459, 2013.

[40] D. D’Amours, F. R. Sallmann, V. M. Dixit, and G. G. Poirier, "Gain-of-function of poly(ADP-ribose) polymerase-1 upon cleavage by apoptotic proteases: implications for apoptosis," Journal of Cell Science, vol. 114, no. 20, pp. 3771-3778, 2001.

[41] J. H. Distler, T. Strapatsas, D. Huscher et al., "Dysbalance of angiogenic and angiostatic mediators in patients with mixed connective tissue disease," Annals of the Rheumatic Diseases, vol. 70, no. 7, pp. 1197-1202, 2011.

[42] P. K. Kaiser, "Emerging therapies for neovascular age-related macular degeneration: drugs in the pipeline," Ophthalmology, vol. 120, no. 5, Supplement, pp. S11-S15, 2013.

[43] S. Rezzola, M. Belleri, D. Ribatti, C. Costagliola, M. Presta, and F. Semeraro, "A novel ex vivo murine retina angiogenesis (EMRA) assay," Experimental Eye Research, vol. 112, pp. 51-56, 2013.

[44] R. Seki, S. Yamagishi, T. Matsui et al., "Pigment epitheliumderived factor (PEDF) inhibits survival and proliferation of VEGF-exposed multiple myeloma cells through its antioxidative properties," Biochemical and Biophysical Research Communications, vol. 431, pp. 693-697, 2013.

[45] A. Stahl, M. T. Stumpp, A. Schlegel et al., "Highly potent VEGFA-antagonistic DARPins as anti-angiogenic agents for topical and intravitreal applications," Angiogenesis, vol. 16, pp. 101-111, 2013.

[46] S. Nakao, M. Arima, K. Ishikawa et al., "Intravitreal antiVEGF therapy blocks inflammatory cell infiltration and re-entry into the circulation in retinal angiogenesis," Investigative Ophthalmology \& Visual Science, vol. 53, pp. 4323-4328, 2012.

[47] I. A. Bhutto, D. S. McLeod, T. Hasegawa et al., "Pigment epithelium-derived factor (PEDF) and vascular endothelial growth factor (VEGF) in aged human choroid and eyes with age-related macular degeneration," Experimental Eye Research, vol. 82, no. 1, pp. 99-110, 2006.

[48] J. A. Stefater III, I. Lewkowich, S. Rao et al., "Regulation of angiogenesis by a non-canonical Wnt-Flt1 pathway in myeloid cells," Nature, vol. 474, no. 7352, pp. 511-515, 2011.

[49] A. Klettner, A. Kauppinen, J. Blasiak, J. Roider, A. Salminen, and K. Kaarniranta, "Cellular and molecular mechanisms of age-related macular degeneration: from impaired autophagy to neovascularization," The International Journal of Biochemistry \& Cell Biology, vol. 45, pp. 1457-1467, 2013.

[50] W. M. Haddad, G. Coscas, and G. Soubrane, "Age-related macular degeneration and apoptosis," Journal Francais d'Ophtalmologie, vol. 26, no. 3, pp. 307-311, 2003. 
[51] J. L. Dunaief, T. Dentchev, G. S. Ying, and A. H. Milam, “The role of apoptosis in age-related macular degeneration," Archives of Ophthalmology, vol. 120, no. 11, pp. 1435-1442, 2002.

[52] N. Liadis, K. Murakami, M. Eweida et al., "Caspase-3dependent $\beta$-cell apoptosis in the initiation of autoimmune diabetes mellitus," Molecular and Cellular Biology, vol. 25, no. 9, pp. 3620-3629, 2005.

[53] J. M. Matés, "Effects of antioxidant enzymes in the molecular control of reactive oxygen species toxicology," Toxicology, vol. 153, no. 1-3, pp. 83-104, 2000.

[54] L. M. Sadaba, P. Fernandez-Robredo, J. A. Rodríguez, and A. García-Layana, "Antioxidant effects of vitamins C and E, multivitamin-mineral complex and flavonoids in a model of retinal oxidative stress: the ApoE-deficient mouse," Experimental Eye Research, vol. 86, no. 3, pp. 470-479, 2008.

[55] I. Jialal, S. Devaraj, and N. Kaul, "The effect of $\alpha$-Tocopherol on monocyte proatherogenic activity," Journal of Nutrition, vol. 131, pp. 389S-394S, 2001.

[56] D. Zhang, M. Al-Hendy, G. Richard-Davis, V. MontgomeryRice, V. Rajaratnam, and A. Al-Hendy, "Antiproliferative and proapoptotic effects of epigallocatechin gallate on human leiomyoma cells," Fertility and Sterility, vol. 94, no. 5, pp. 18871893, 2010.

[57] Z. Ungvari, Z. Orosz, A. Rivera, N. Labinskyy, Z. Xiangmin, and A. Csiszae, "Resveratrol increases vascular oxidative stress resistance," The FASEB Journal, vol. 21, p. 576.2, 2007.

[58] R. Medzhitov and C. Janeway Jr., "Innate immunity," The New England Journal of Medicine, vol. 343, no. 5, pp. 338-344, 2000.

[59] S. Cao, G. B. Walker, X. Wang, J. Z. Cui, and J. A. Matsubara, "Altered cytokine profiles of human retinal pigment epithelium: oxidant injury and replicative senescence," Molecular Vision, vol. 19, pp. 718-728, 2013.

[60] F. Parmeggiani, D. Gemmati, C. Costagliola, A. Sebastiani, and C. Incorvaia, "Predictive role of C677T MTHFR polymorphism in variable efficacy of photodynamic therapy for neovascular age-related macular degeneration," Pharmacogenomics, vol. 10, no. 1, pp. 81-95, 2009.

[61] F. Cruz-Guilloty, A. M. Saeed, J. J. Echegaray et al., "Infiltration of proinflammatory $\mathrm{ml}$ macrophages into the outer retina precedes damage in a mouse model of age-related macular degeneration," International Journal of Inflammation, vol. 2013, Article ID 503725, 12 pages, 2013.

[62] R. P. Casaroli-Marano, J. Peinado-Onsurbe, M. Reina, B. Staels, J. Auwerx, and S. Vilaró, "Lipoprotein lipase in highly vascularized structures of the eye," Journal of Lipid Research, vol. 37, no. 5, pp. 1037-1044, 1996.

[63] D. H. Anderson, K. C. Talaga, A. J. Rivest, E. Barron, G. S. Hageman, and L. V. Johnson, "Characterization of $\beta$ amyloid assemblies in drusen: the deposits associated with aging and agerelated macular degeneration," Experimental Eye Research, vol. 78, no. 2, pp. 243-256, 2004.

[64] G. S. Hageman, P. J. Luthert, N. H. V. Chong, L. V. Johnson, D. H. Anderson, and R. F. Mullins, "An integrated hypothesis that considers drusen as biomarkers of immune-mediated processes at the RPE-Bruch's membrane interface in aging and age-related macular degeneration," Progress in Retinal and Eye Research, vol. 20, no. 6, pp. 705-732, 2001.

[65] J. J. Alexander, L. Bao, A. Jacob, D. M. Kraus, V. M. Holers, and R. J. Quigg, "Administration of the soluble complement inhibitor, Crry-Ig, reduces inflammation and aquaporin 4 expression in lupus cerebritis," Biochimica et Biophysica Acta, vol. 1639, no. 3, pp. 169-176, 2003.
[66] D. A. Newsome, M. Swartz, N. C. Leone, R. C. Elston, and E. Miller, "Oral zinc in macular degeneration," Archives of Ophthalmology, vol. 106, no. 2, pp. 192-198, 1988.

[67] S. Richer, W. Stiles, L. Statkute et al., "Double-masked, placebocontrolled, randomized trial of lutein and antioxidant supplementation in the intervention of atrophic age-related macular degeneration: the Veterans LAST study (Lutein Antioxidant Supplementation Trial)," Optometry, vol. 75, no. 4, pp. 216-230, 2004.

[68] M. Stur, M. Tittl, A. Reitner, and V. Meisinger, "Oral zinc and the second eye in age-related macular degeneration," Investigative Ophthalmology and Visual Science, vol. 37, no. 7, pp. 1225-1235, 1996.

[69] D. A. Newsome, "A randomized, prospective, placebocontrolled clinical trial of a novel zinc-monocysteine compound in age-related macular degeneration," Current Eye Research, vol. 33, no. 7, pp. 591-598, 2008.

[70] S. Richer, "Multicenter ophthalmic and nutritional age-related macular degeneration study-part 2: antioxidant intervention and conclusions," Journal of the American Optometric Association, vol. 67, no. 1, pp. 30-49, 1996.

[71] J. Feher, B. Kovacs, I. Kovacs, M. Schvoller, A. Papale, and C. B. Gabrieli, "Improvement of visual functions and fundus alterations in early age-related macular degeneration treated with a combination of acetyl-L-carnitine, n-3 fatty acids, and coenzyme Q10," Ophthalmologica, vol. 219, no. 3, pp. 154-166, 2005.

[72] E. W. Chong, A. J. Kreis, T. Y. Wong, J. A. Simpson, and R. H. Guymer, "Dietary $\omega$-3 fatty acid and fish intake in the primary prevention of age-related macular degeneration: a systematic review and meta-analysis," Archives of Ophthalmology, vol. 126, no. 6, pp. 826-833, 2008.

[73] W. G. Christen, D. A. Schaumberg, R. J. Glynn, and J. E. Buring, "Dietary $\omega$-3 fatty acid and fish intake and incident age-related macular degeneration in women," Archives of Ophthalmology, vol. 129, no. 7, pp. 921-929, 2011.

[74] R. van Leeuwen, S. Boekhoorn, J. R. Vingerling et al., "Dietary intake of antioxidants and risk of age-related macular degeneration," The Journal of the American Medical Association, vol. 294, no. 24, pp. 3101-3107, 2005.

[75] V. Flood, W. Smith, J. J. Wang, F. Manzi, K. Webb, and P. Mitchell, "Dietary antioxidant intake and incidence of early agerelated maculopathy: the Blue Mountains Eye Study," Ophthalmology, vol. 109, no. 12, pp. 2272-2278, 2002.

[76] E. Chow, J. M. Seddon, B. Rosner, W. C. Willett, and S. E. Hankinson, "Prospective study of intake of fruits, vegetables, vitamins, and carotenoids and risk of age-related maculopathy," Archives of Ophthalmology, vol. 122, no. 6, pp. 883-892, 2004.

[77] G. M. van den Langenberg, J. A. Mares-Perlman, R. Klein, B. E. K. Klein, W. E. Brady, and M. Palta, "Associations between antioxidant and zinc intake and the 5-year incidence of early age-related maculopathy in the beaver dam eye study," The American Journal of Epidemiology, vol. 148, no. 2, pp. 204-214, 1998.

[78] M. S. Moeller, N. Parekh, L. L. Tinker et al., "Associations between intermediate age-related macular degeneration and lutein and zeaxanthin in the Carotenoids in Age-Related Eye Disease Study (CAREDS): ancillary study of the Women's Health Initiative," Archives of Ophthalmology, vol. 124, no. 8, pp. 1151-1162, 2006.

[79] H. Taylor, G. Tikellis, L. Robman et al., "Vitamin E supplementation and macular degeneration: randomised controlled trial," British Medical Journal, vol. 325, no. 7354, pp. 11-14, 2002. 
[80] W. G. Hodge, H. M. Schachter, D. Barnes et al., "Efficacy of $\omega$ 3 fatty acids in preventing age-related macular degeneration: a systematic review," Ophthalmology, vol. 113, no. 7, pp. 1165-1173, 2006.

[81] E. W. Chong, T. Y. Wong, A. J. Kreis, J. A. Simpson, and R. H. Guymer, "Dietary antioxidants and primary prevention of age related macular degeneration: systematic review and metaanalysis," The British Medical Journal, vol. 335, no. 7623, pp. 755759, 2007.

[82] E. H. Soused, C. Delcourt, G. Querques et al., "Nutritional AMD treatment 2 study group. Oral docosahexaenoic acid in the prevention of exudative age-related macular degeneration: the nutritional AMD treatment 2 study," Ophthalmology, vol. 120, no. 8, pp. 1619-1631, 2013.

[83] J. M. Teikari, L. Laatikainen, J. Virtamo et al., "Six-year supplementation with alpha-tocopherol and beta-carotene and agerelated maculopathy," Acta Ophthalmologica Scandinavica, vol. 76, no. 2, pp. 224-229, 1998.

[84] O. P. Heinonen, J. K. Huttunen, D. Albanes et al., “The alphatocopherol, beta-carotene lung cancer prevention study: design, methods, participant characteristics, and compliance. The ATBC Cancer Prevention Study Group," Annals of Epidemiology, vol. 4, no. 1, pp. 1-10, 1994.

[85] G. E. Goodman, G. S. Omenn, M. D. Thornquist, B. Lund, B. Metch, and I. Gylys-Colwell, "The Carotene and Retinol Efficacy Trial (CARET) to prevent lung cancer in high-risk populations: pilot study with cigarette smokers," Cancer Epidemiology Biomarkers and Prevention, vol. 2, no. 4, pp. 389-396, 1993.

[86] G. S. Omenn, G. E. Goodman, M. D. Thornquist et al., "Effects of a combination of beta carotene and vitamin A on lung cancer and cardiovascular disease," The New England Journal of Medicine, vol. 334, no. 18, pp. 1150-1155, 1996.

[87] J. S. Tan, J. J. Wang, V. Flood, E. Rochtchina, W. Smith, and P. Mitchell, "Dietary antioxidants and the long-term incidence of age-related macular degeneration: the Blue Mountains Eye Study," Ophthalmology, vol. 115, no. 2, pp. 334-341, 2008.

[88] J. H. Olson, J. C. Erie, and S. J. Bakri, "Nutritional supplementation and age-related macular degeneration," Seminars in Ophthalmology, vol. 26, no. 3, pp. 131-136, 2011.

[89] Food and Nutrition Board, Institute of Medicine, "Copper," in Dietary Reference Intakes for Vitamin A, Vitamin K, Arsenic, Boron, Chromium, Copper, Iodine, Iron, Manganese, Molybdenum, Nickel, Silicon, Vanadium, and Zinc, pp. 224-257, National Academy Press, Washington, DC, USA, 2001.

[90] Z. B. Kang, Y. Ge, Z. Chen et al., "Adenoviral gene transfer of Caenorhabditis elegans n-3 fatty acid desaturase optimizes fatty acid composition in mammalian cells," Proceedings of the National Academy of Sciences of the United States of America, vol. 98, no. 7, pp. 4050-4054, 2001.

[91] M. E. Pennesi, M. Neuringer, and R. J. Courtney, "Animal models of age related macular degeneration," Molecular Aspects of Medicine, vol. 33, pp. 487-509, 2012.

[92] T. Koto, N. Nagai, H. Mochimaru et al., "Eicosapentaenoic acid is anti-inflammatory in preventing choroidal neovascularization in mice," Investigative Ophthalmology \& Visual Science, vol. 48, no. 9, pp. 4328-4334, 2007.

[93] J. Tuo, C. M. Bojanowski, M. Zhou et al., "Murine Ccl2/Cx3cr1 deficiency results in retinal lesions mimicking human agerelated macular degeneration," Investigative Ophthalmology and Visual Science, vol. 48, no. 8, pp. 3827-3836, 2007.
[94] C. C. Chan, R. J. Ross, D. Shen et al., "Ccl2/Cx3cr1-deficient mice: an animal model for age-related macular degeneration," Ophthalmic Research, vol. 40, no. 3-4, pp. 124-128, 2008.

[95] J. Tuo, R. J. Ross, A. A. Herzlich et al., "A high omega-3 fatty acid diet reduces retinal lesions in a murine model of macular degeneration," The American Journal of Pathology, vol. 175, no. 2, pp. 799-807, 2009.

[96] R. W. Bellhorn, C. D. King, G. D. Aguirre, H. Ripps, I. M. Siegel, and H. C. Tsai, "Pigmentary abnormalities of the macula in rhesus monkeys: clinical observations," Investigative Ophthalmology and Visual Science, vol. 21, no. 6, pp. 771-781, 1981.

[97] T. J. Stafford, S. H. Anness, and B. S. Fine, "Spontaneous degenerative maculopathy in the monkey," Ophthalmology, vol. 91, no. 5, pp. 513-521, 1984.

[98] M. G. Nicolas, K. Fujiki, K. Murayama et al., "Studies on the mechanism of early onset macular degeneration in cynomolgus (Macaca fascicularis) monkeys. I. Abnormal concentrations of two proteins in the retina," Experimental Eye Research, vol. 62, no. 3, pp. 211-219, 1996.

[99] S. Umeda, M. T. Suzuki, H. Okamoto et al., "Molecular composition of drusen and possible involvement of anti-retinal autoimmunity in two different forms of macular degeneration in cynomolgus monkey (Macaca fascicularis)," The FASEB Journal, vol. 19, no. 12, pp. 1683-1685, 2005.

[100] M. Neuringer, P. J. Francis, L. Renner, A. Weiss, and B. G. Jeffrey, "Atrophic macular degeneration in rhesus monkeys deficient in xanthophylls and n-3 fatty acids," ARVO Abstract, Association for Research in Vision and Ophthalmology, 2010.

[101] P. Gouras, L. Ivert, M. Neuringer, and J. A. Mattison, “Topographic and age-related changes of the retinal epithelium and Bruch's membrane of rhesus monkeys," Graefe's Archive for Clinical and Experimental Ophthalmology, vol. 248, no. 7, pp. 973-984, 2010.

[102] L. Renner, S. Hurst, T. McGill et al., "Progression of atrophic macular degeneration in rhesus monkeys deficient in lutein/ zeaxanthin and omega-3 fatty acids," ARVO Abstract, Association for Research in Vision and Ophthalmology, 2013.

[103] F. M. Barker II, D. M. Snodderly, E. J. Johnson et al., "Nutritional manipulation of primate retinas. V: effects of lutein, zeaxanthin, and n-3 fatty acids on retinal sensitivity to blue-light-induced damage," Investigative Ophthalmology \& Visual Science, vol. 52, pp. 3934-3942, 2011.

[104] T. Tsuzuki, A. Shibata, Y. Kawakami, K. Nakagawa, and T. Miyazawa, "Conjugated eicosapentaenoic acid inhibits vascular endothelial growth factor-induced angiogenesis by suppressing the migration of human umbilical vein endothelial cells," Journal of Nutrition, vol. 137, no. 3, pp. 641-646, 2007.

[105] N. Papadopoulos, J. Martin, Q. Ruan et al., "Binding and neutralization of vascular endothelial growth factor (VEGF) and related ligands by VEGF Trap, ranibizumab and bevacizumab," Angiogenesis, vol. 15, pp. 171-185, 2012.

[106] D. Richard, K. Kefi, U. Barbe, P. Bausero, and F. Visioli, "Polyunsaturated fatty acids as antioxidants," Journal of Regenerative Medicine and Tissue Engineering, vol. 2, pp. 383-393, 2008.

[107] E. Banumathi, R. Haribalaganesh, S. S. P. Babu, N. S. Kumar, and G. Sangiliyandi, "High-yielding enzymatic method for isolation and culture of microvascular endothelial cells from bovine retinal blood vessels," Microvascular Research, vol. 77, no. 3, pp. 377-381, 2009.

[108] S. Sheikpranbabu, R. Haribalaganesh, E. Banumathi, N. Sirishkumar, K. J. Lee, and S. Gurunathan, "Pigment 
epithelium-derived factor inhibits advanced glycation endproduct-induced angiogenesis and stimulates apoptosis in retinal endothelial cells," Life Sciences, vol. 85, pp. 719-731, 2009.

[109] I. Morita, Y. W. Zhang, and S. I. Murota, "Eicosapentaenoic acid protects endothelial cell function injured by hypoxia/ reoxygenation," Annals of the New York Academy of Sciences, vol. 947, pp. 394-397, 2001.

[110] P. K. Mukherjee, V. L. Marcheselli, C. N. Serhan, and N. G. Bazan, "Neuroprotectin D1: a docosahexaenoic acid-derived docosatriene protects human retinal pigment epithelial cells from oxidative stress," Proceedings of the National Academy of Sciences of the United States of America, vol. 101, no. 22, pp. 84918496, 2004.

[111] A. J. Chucair, N. P. Rotstein, J. P. Sangiovanni, A. During, E. Y. Chew, and L. E. Politi, "Lutein and zeaxanthin protect photoreceptors from apoptosis induced by oxidative stress: relation with docosahexaenoic acid," Investigative Ophthalmology and Visual Science, vol. 48, no. 11, pp. 5168-5177, 2007.

[112] R. Kannan, N. Zhang, P. G. Sreekumar et al., "Stimulation of apical and basolateral vascular endothelial growth factor-A and vascular endothelial growth factor- $\mathrm{C}$ secretion by oxidative stress in polarized retinal pigment epithelial cells," Molecular Vision, vol. 12, pp. 1649-1659, 2006.

[113] D. B. Kagan, H. Liu, and C. M. Hutnik, "Efficacy of various antioxidants in the protection of the retinal pigment epithelium from oxidative stress," Clinical Ophthalmology, vol. 6, pp. 14711476, 2012.

[114] J. Evans, "Antioxidant supplements to prevent or slow down the progression of AMD: a systematic review and meta-analysis," Eye, vol. 22, no. 6, pp. 751-760, 2008.

[115] A. Sujak, J. Gabrielska, W. Grudziński, R. Borc, P. Mazurek, and W. I. Gruszecki, "Lutein and zeaxanthin as protectors of lipid membranes against oxidative damage: the structural aspects," Archives of Biochemistry and Biophysics, vol. 371, no. 2, pp. 301307, 1999. 


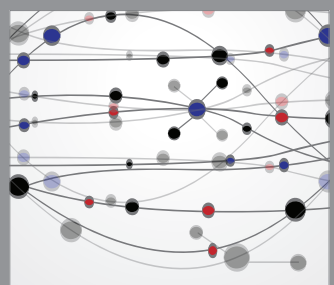

The Scientific World Journal
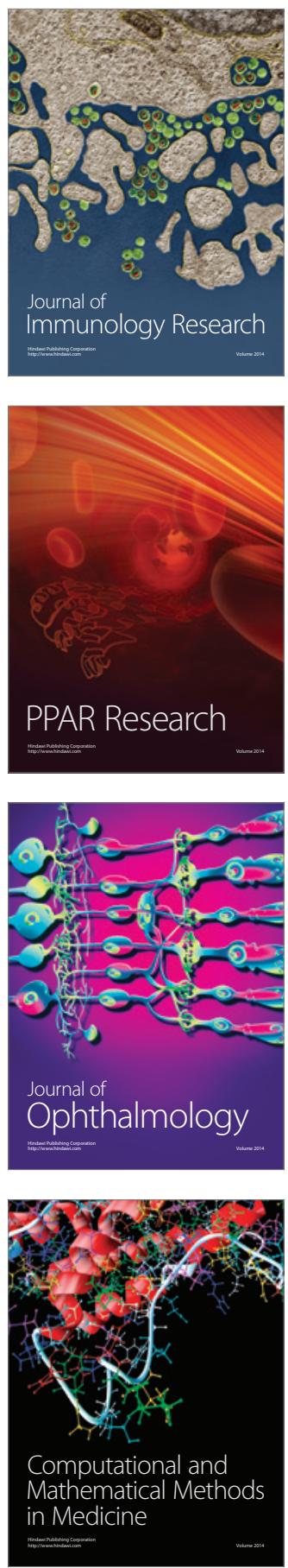

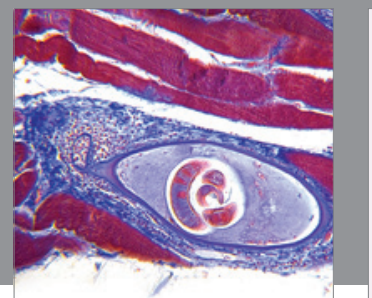

Gastroenterology

Research and Practice
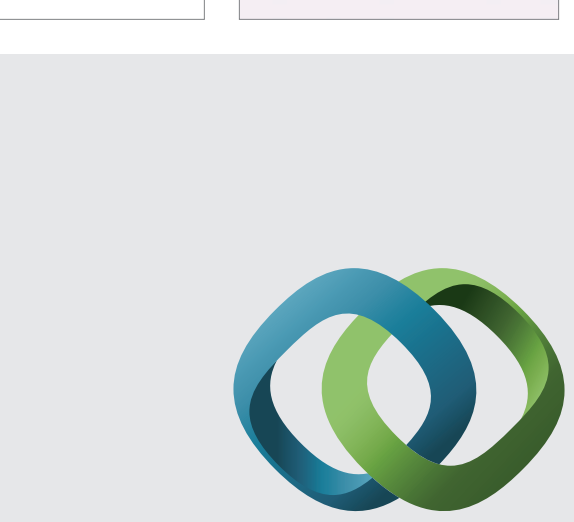

\section{Hindawi}

Submit your manuscripts at

http://www.hindawi.com
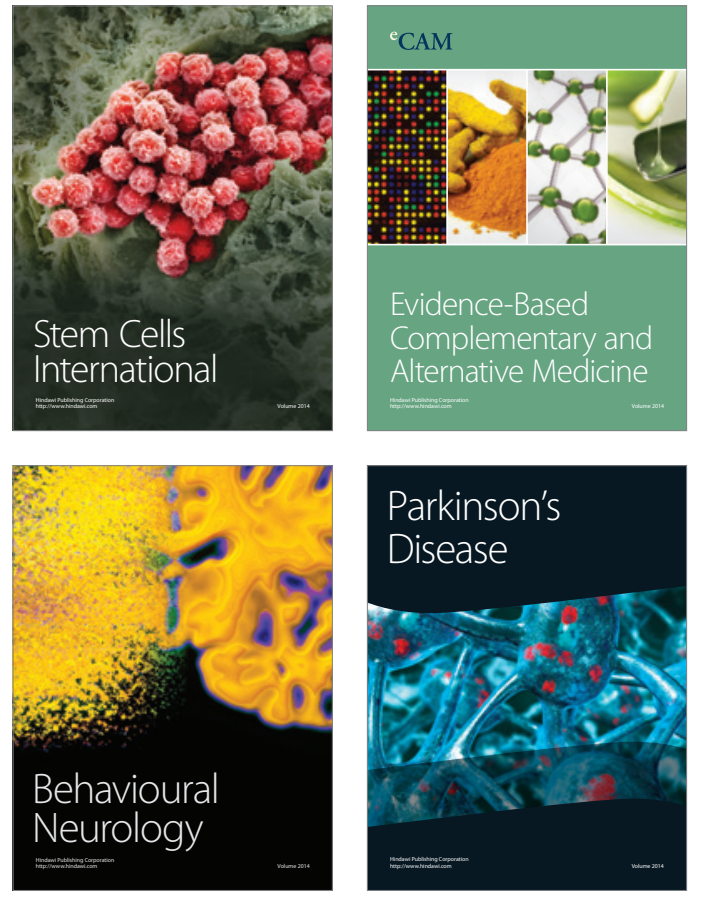
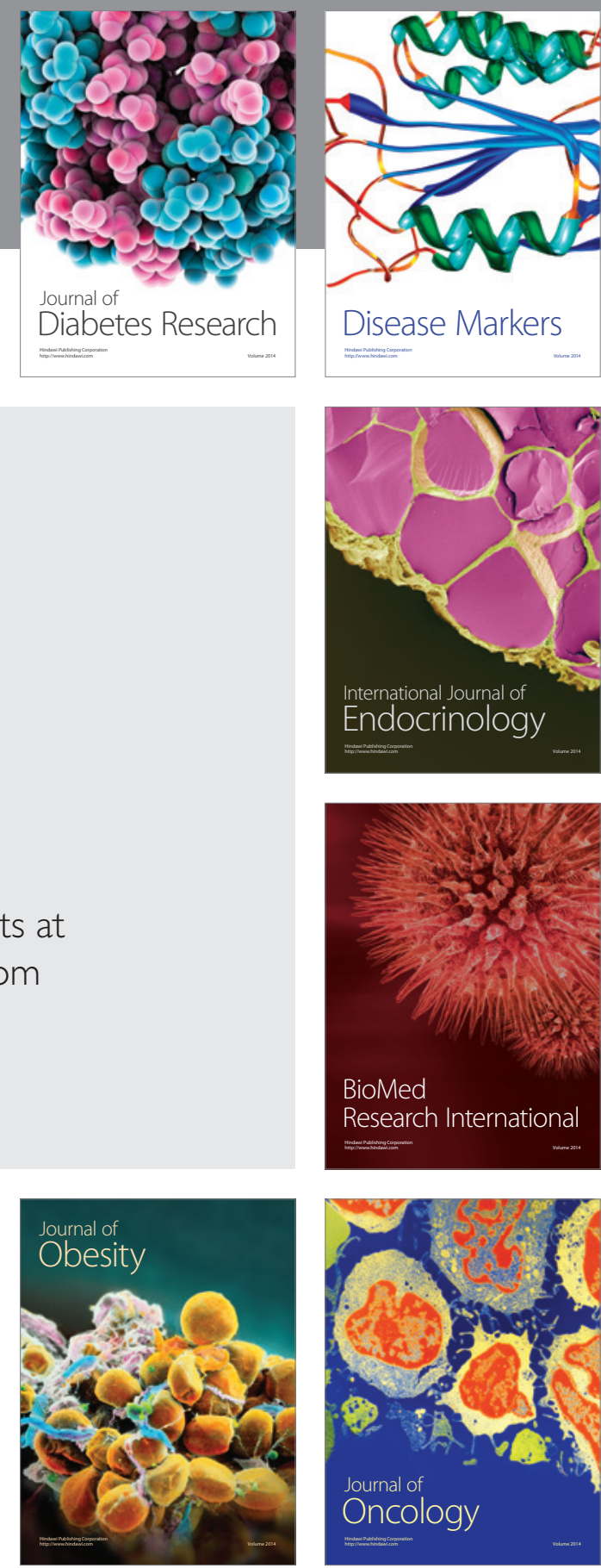

Disease Markers
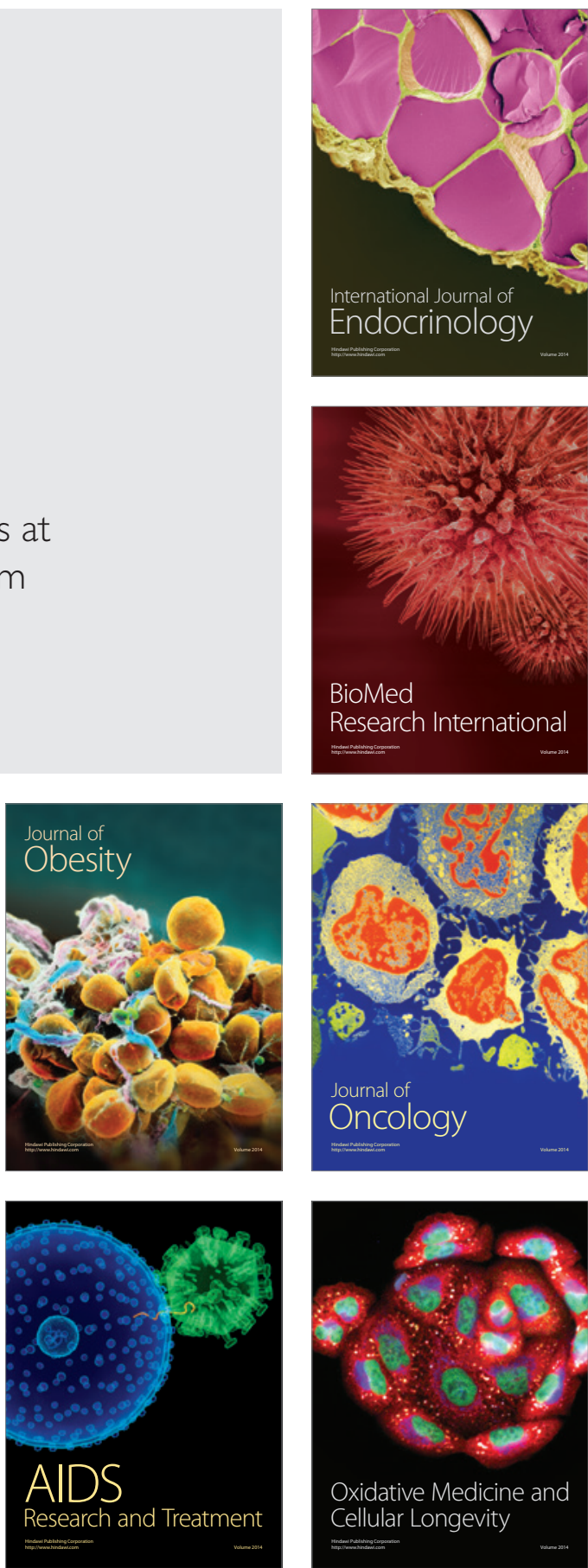